\title{
A spin to preserve contrast: Taiwanese tone sandhi ${ }^{1}$
}

\author{
Lian-Hee Wee iD \\ Department of English Language and Literature, Hong Kong Baptist University, Hong Kong \\ E-mail: lianhee@hkbu.edu.hk
}

\begin{abstract}
Chain shifts, particularly circular ones such as the tone sandhi of Taiwanese Min, are easy to describe but the phonological underpinnings are difficult to explain. This paper synthesises ideas of markedness and contrast preservation to propose that the Taiwanese Min tone circle might historically first have been triggered by a ban against contour tones in non-final positions. This sets Preserve Contrast off into a diachronic chain reaction to maintain underlying contrasts in surface forms. This eventually settles into the modern grammar as antifaithfulness. While the historical trigger is speculative, the analysis proposed in this paper does find indirect corroboration in production and "back-construction" experiments that would have otherwise yielded irreconcilable data.
\end{abstract}

Keywords: tone sandhi, chain shift, preserve contrast, contour tones, markedness, Taiwanese Min

\section{Introduction}

Chain shifts, particularly circular ones such as the tone sandhi of Taiwanese Min, are challenging because there are two questions that must be simultaneously answered: (i) how does one ascertain the derived target, and (ii) why do all locus of alternations not just neutralise to the target at the end of the chain. In some sense, both (i) and (ii) are the same question although, with circular chain shifts, (ii) is discernible as a kind of "turtles all the way down" effect that would yield an infinite loop in languages where chain shifts complete a circle. ${ }^{2}$

This paper looks into the case of Taiwanese Min, and proposes that the pattern arose out of a ban on non-final tone contours. These neutralised non-final tones set in motion the need for contrast preservation which consequently engenders the modern tone circle of Taiwanese Min. This account makes a prediction on the diachronic development of the Min tone circle. Vindication from historical linguistics will have to await discovery of corroborative documents or

\footnotetext{
${ }^{1}$ Linguistics aside, Akin taught me a very specific, valuable lesson (circa 2001) that I have taken care to pass on to as many students as possible. He taught me how a student could see things from the perspective of his professors. This enabled to me to learn so much more deeply into what others (including my students) try to teach me and also opened many doors that might have otherwise been shut. Thank you Akin, and happy $60^{\text {th }}$ birthday! I also wish to thank Seung-hun Lee and Will Bennet for their painstaking work as editors. Thanks also to Winnie H.Y. Cheung, Mingxing Li, Olivia N-W. Tam, and two anonymous reviewers for their many useful comments. All remaining errors are mine.

${ }^{2}$ This is particularly problematic for output-driven frameworks such as Optimality Theory (OT) where grammars must be eventually and fully idempotent (Tesar 2014, especially pp. 22-25, 150-153).
}

(C) 2019 The authors. This work is licensed under the Creative Commons Attribution 4.0 International License. 
comparative studies of dialectology on classical Min reconstruction. For now, this paper's more modest goal is to provide a theoretical model that correctly generates the Taiwanese tone sandhi circle, something that, to the extent of my knowledge, has hitherto not been wholly successful.

Section 2 presents the basic facts of Taiwanese tone sandhi, after which my account will be offered in section 3. Section 4 offers a review of relevant precedent works in order to contextualise the intellectual debts underlying this paper. Section 5 then provides a brief conclusion.

\section{Basic facts of Taiwanese tones and sandhi}

The basic patterns of Taiwanese Min that concern this paper stem from an inventory of five tones from unchecked syllables (i.e. syllables not closed by obstruents). These tones alternate depending on whether or not the syllable is phrase-final. The tonal inventory and the target of tone sandhi are given in (1) below.

(1) Taiwanese Min tone basics (Peng 1997, Myers and Tsay 2008, among others)

a. Inventory of Taiwanese Min tones

\begin{tabular}{|c|c|l|}
\hline Tone value & Tone representation & \multicolumn{1}{|c|}{ Example } \\
\hline$[55]$ & $\mathrm{Hr}, \mathrm{h}$ & $\mathrm{si}^{\mathrm{Hr}, \mathrm{h}}$ 'poetry' \\
\hline$[24]$ & $\mathrm{Lr}, \mathrm{h}$ & $\mathrm{si}^{\mathrm{L}}$ Lr.lh 'time' \\
\hline$[51]$ & $\mathrm{Hr}, \mathrm{hl}$ & $\mathrm{si}^{\mathrm{irrh}}$ 'temple' \\
\hline$[33]$ & $\mathrm{Lr}, \mathrm{h}$ & $\mathrm{si}^{\mathrm{Hr}, \mathrm{hl}}$ 'die' \\
\hline$[21]$ & $\mathrm{Lr}, \mathrm{hl}$ & $\mathrm{si}^{\mathrm{Lr}, \mathrm{hl}}$ 'four' \\
\hline
\end{tabular}

b. Sandhi in non-final positions

\begin{tabular}{|c|c|c|}
\hline Sandhi rule & & Example \\
\hline $\mathrm{Hr}, \mathrm{h} \rightarrow \mathrm{Lr}, \mathrm{h}$ & \multirow{5}{*}{$L_{1} \sigma$} & $\mathbf{s i}{ }^{\mathrm{Hr}, \mathbf{h} \rightarrow \mathbf{L r}, \mathbf{h}}$ bun ${ }^{\mathrm{Lr}, \mathrm{lh}}$ 'poetry and prose' \\
\hline Lr.lh $\rightarrow$ Lr,h & & si $^{\text {Lr.lh } \rightarrow \text { Lr,h }} \mathrm{kan}^{\mathrm{Hr}, \mathrm{h}}$ 'time span; time' \\
\hline $\mathrm{Lr}, \mathrm{h} \rightarrow \mathrm{Lr}, \mathrm{hl}$ & & $\mathbf{s i}^{\mathbf{L r}, \mathbf{h} \rightarrow \mathbf{L r}, \mathbf{h l}}$ tsin $^{\mathrm{Hr}, \mathrm{h}}$ 'temple monk' \\
\hline $\mathrm{Hr}, \mathrm{hl} \rightarrow \mathrm{Hr}, \mathrm{h}$ & & $\mathbf{s i}^{\mathrm{Hr}, \mathbf{h l} \rightarrow \mathrm{Hr}, \mathbf{h}}$ la ${ }^{\mathrm{Lr}, \mathrm{lh}}$ 'dead people' \\
\hline $\mathrm{Lr}, \mathrm{hl} \rightarrow \mathrm{Hr}, \mathrm{hl}$ & & 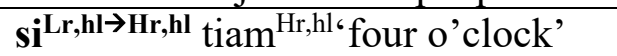 \\
\hline
\end{tabular}

c. Diagrammatic representation of the tone circle

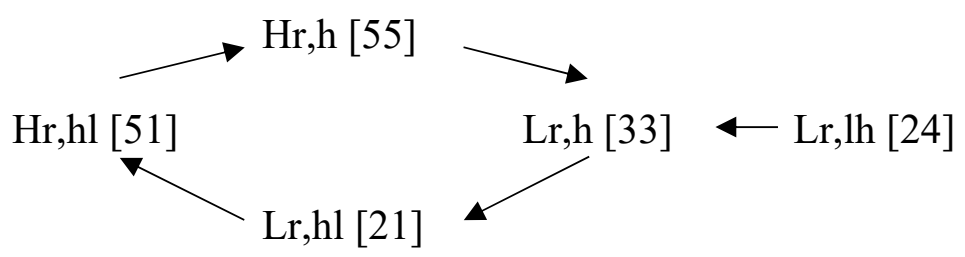

The tonal values of the Taiwanese Min inventory are given using Chao's (1930) system, where [1] is lowest and [5] highest, reinterpreted using a combination of registers ([Hr] for High register and $[\mathrm{Lr}]$ for low) and tonal features $[\mathrm{h}(\mathrm{igh})]$ and $[1(\mathrm{ow})]$ to describe the pitch contour (thus [hl] is a falling contour). The use of register for Taiwanese/Xiamen goes back to Wang (1967), and the practice became popularised through Yip (1980), Bao (1999), inter alia.

In (1a), the tones of each syllable are as given when the syllable is read in isolation or when it occurs in a phrase-final position. In (1b), the tones can be seen to alternate when followed by another syllable. The citation forms as given in (1a) are assumed to be underlying, and the tones 
are assumed to undergo sandhi in (1b). An assumption otherwise would entail a one-to-many mapping from $\mathrm{Lr}$, h to both $\mathrm{Lr}, \mathrm{lh}$ and $\mathrm{Hr}$,h, rendering all mathematical modelling impossible. Following the assumption that sandhi applies only in non-phrase-final positions, (1c) provides a diagrammatic summary of the tone sandhi patterns. As is evident, each step along the sandhi circle changes either register or contour, but never both. As far as has been reported, the sandhi patterns are robust and without exception. ${ }^{3}$

Taiwanese Min is by no means unique in having chain shifts. In fact, this is almost characteristic of languages in the Southern Min family of which Taiwanese Min is a member. The sandhi patterns of Southern Min languages are sampled below with Xiamen, Teochew, and Hainanese.

(2) Other Southern Min tone chains

a. Xiamen (Yuan 1989: 245, Wang 1967)

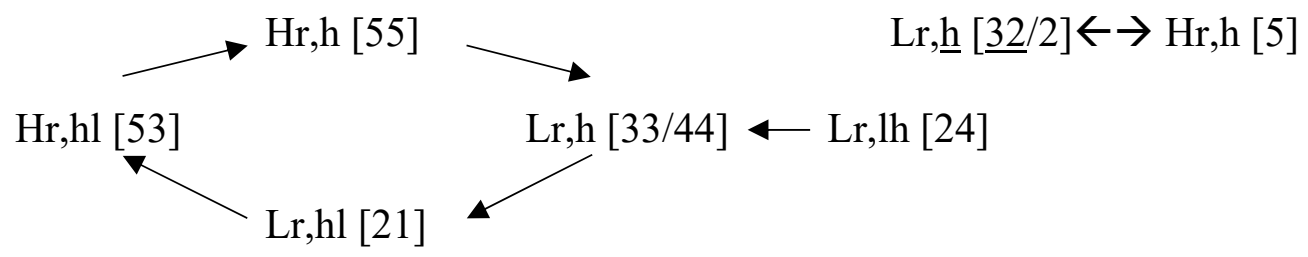

b. Teochew (Cai 1991: 5)

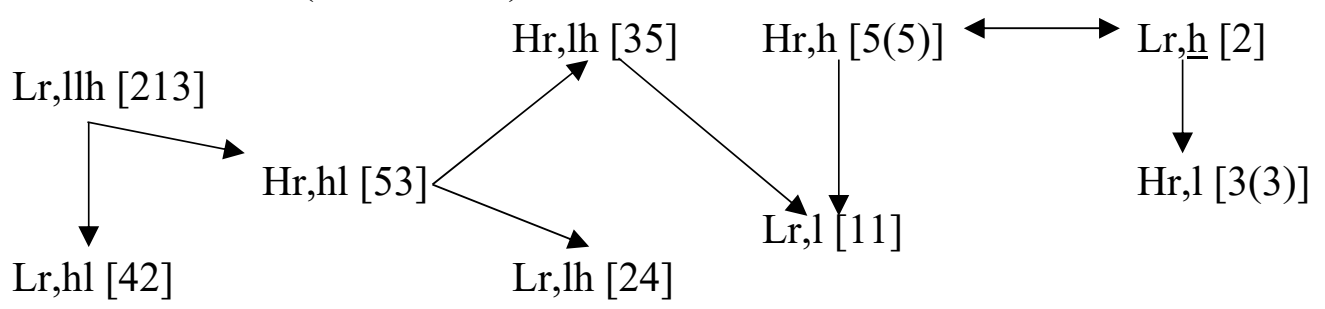

c. Hainanese (Yun 1987: 14)

Lr,hl [늘

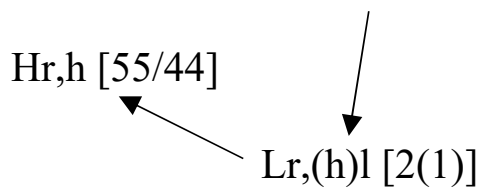

Lr,h [33]

$\mathrm{Hr}, \mathrm{hl}[\underline{51}]$

Xiamen (2a) and Taiwanese are, de facto, quite identical except for minor differences in tone values. For that reason, phonological literature that treats one often also cross-references the other. Teochew ( $2 \mathrm{~b})$ involves splitting which is conditioned by tone register assimilation to the following tone (Bao 1999: 81-82). Hainanese (2c) involves some chain shifts although there are tones that do not participate in tone sandhi. These languages are historically related and this may be a reason why they all show chain-shifting.

\footnotetext{
${ }^{3}$ Although see Zhang and Lai (2008), and Zhang, Lai and Sailor (2011) for counter claims on productivity. This issue is discussed in section 3.3 of this paper.
} 
However, any historical connection must be tenuous as is obvious when one looks at the corresponding Middle Chinese tone categories. ${ }^{4}$ Middle Chinese has eight tonal categories consisting of Ping, Shang, $\mathrm{Qu}$, and $\mathrm{Ru}$, each splitting into Yin and Yang registers (see Pulleyblank 1984: 140, amongst other good references,). As it turns out, category shifts are inconsistent across the languages with respect to the sandhi patterns in (2). For example, $\mathrm{Hr}, \mathrm{h} \rightarrow \mathrm{Lr}$, h in Taiwanese/Xiamen is a shift from the Yin Ping category to Yang Qu. In Teochew, the Yin Ping tone would be Hr,l which does not sandhi. Consequently, one may infer that the sandhi patterns for these sister languages have evolved independently in their respective communities. As such, it may not be possible (nor in fact necessary) to find an account that covers all the patterns across the Southern Min group of languages. That seems to be the general approach taken in the phonological literature that addresses the sandhi patterns of Taiwanese and/or Xiamen, although the justification has rarely, if ever, been explicitly made.

\section{Markedness-induced diachronic preservation of contrast}

The sandhi circle is reminiscent of the snake swallowing its own tail, the Ouroboros, which although is itself a symbol of infinity, is one that has a head. The question for Taiwanese Min is which among the five tones is the beginning of this sandhi circle in (1c). This paper advocates a two-part solution: the first part is to postulate which among the five tones is the Ouroboros' head. Thomas (2008) suggests Lr,lh as the starting point, but I shall later explain that this is not viable. Instead, I shall suggest that the chain is triggered by a general markedness against final contours (Zhang 2002). The second part of my solution accepts Barrie's (2006) insight that contrast preservation (Lubowicz 2003, 2012) provides impetus for the chain reaction that eventually circles on itself.

\subsection{A diachronic account through contrast preservation}

Lest one forgets, the Taiwanese tones only undergo sandhi in non-final positions. In isolation and in (phrase-)final positions, the citation forms are maintained. ${ }^{5}$ Evidently, faithfulness constraints such as (3) are in order.

\section{IDENT[T]}

Assign one violation mark for any instance where the output tone (register or contour) is not identical to the corresponding input tone contour.

The difficulty is with figuring out what constraint should override those in (3). It should be evident that such a constraint cannot possibly derive the tone circle in (1c). A markedness constraint would serve only to neutralise the underlying distinctions into a relatively unmarked form, and would not yield the result of chain-shifting where the sandhi train stops at every station. Neither would markedness allow the sandhi process to complete a circuit, as that would

\footnotetext{
${ }^{4}$ Because Chinese writing has been unbroken for more than two millennia, historical documents such as rhyme tables and dictionaries allow matching of all modern pronunciation with their Middle Chinese tone categories. The tone inventory of the three languages listed in (2) are tabled below with their tone values and Middle Chinese categories.
}

\begin{tabular}{|c|c|c|c|c|c|c|c|c|}
\hline \multirow{2}{*}{$\begin{array}{l}\text { Middle Chinese } \\
\text { Categories }\end{array}$} & \multicolumn{2}{|c|}{ Ping } & \multicolumn{2}{|c|}{ Shang } & \multicolumn{2}{|c|}{$\mathrm{Qu}$} & \multicolumn{2}{|c|}{$\mathrm{Ru}$} \\
\hline & Yin & Yang & Yin & Yang & Yin & Yang & Yin & Yang \\
\hline Taiwanese/Xiamen & 55 & 24 & & & 11 & 33 & $\underline{32}$ & 5 \\
\hline Teochew & 33 & 55 & 53 & 35 & 213 & 11 & 2 & 5 \\
\hline Hainanese & 44 & 33 & & & & & $\underline{51}$ & $\underline{42}$ \\
\hline
\end{tabular}

\footnotetext{
${ }^{5}$ See Chen (1987) and Truckenbrodt's (1999) optimality theoretical update on the prosodic-syntax interface that
} would define the tone sandhi domain for Xiamen, which also applies equally to Taiwanese Min. 
bring us back to the marked form that triggered the process in the first place. If not markedness then, perhaps antifaithfulness (attempted in Horwood 1999 and Wee 2002)? This, however, may be unable to predict when sandhi would apply to tone register and when to tone contour (Hsiao 2015; more later in section 4.3). Comparative markedness (McCarthy 2003) offers a brake on the sandhi chain since derived forms can now be treated as relatively unmarked if derived markedness is outranked by faithfulness constraints. Such a solution would require every underived tone in Taiwanese Min to undergo sandhi, contrary to fact. The citation forms of the tones do surface in non-final positions. Of the five Taiwanese Min tones, three have contour melodies, and I suggest that (4) below might be the trigger.

\section{*NON-FCTR \\ Assign one violation mark for every contour melody in a non-final position.}

The constraints in (4) should invite little controversy. Zhang's (2002) comprehensive survey of more than 180 languages has convincingly shown the basis for *NON-FCTR as a universal principle. There is also a phonetic basis due presumably to the shorter duration of non-final syllables. As a markedness constraint, (4) is inadequate for a full account of the tone circle in (1c), but it will at least require some tones to undergo sandhi.

Triggering sandhi in non-final positions

\begin{tabular}{|c|c|c|}
\hline $\begin{array}{l}\text { a. } / \mathrm{Hr}, \mathrm{hl} / \\
\text { e.g. } \mathrm{si}^{\mathrm{Hr}, \mathrm{hl} l} \text { 'dead' }\end{array}$ & *NON-FCTR & IDENT[T] \\
\hline \multicolumn{3}{|l|}{ i. Hr,hl } \\
\hline ii. $\mathrm{Hr}, \mathrm{h}$ & & $* !$ \\
\hline \multicolumn{3}{|c|}{ 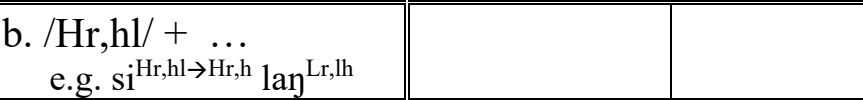 } \\
\hline i. $\quad \mathrm{Hr}, \mathrm{hl}+\ldots$ & $* !$ & \\
\hline ii. $\mathrm{Hr}, \mathrm{h}+\ldots$ & & $*$ \\
\hline \multicolumn{3}{|l|}{$\begin{array}{l}\text { c. } / \mathrm{Lr}, \mathrm{lh} /+\ldots \\
\text { e.g. } \mathrm{si}^{\mathrm{Lr} . \mathrm{lh} \rightarrow \mathrm{Lr}, \mathrm{h}} \mathrm{kan}^{\mathrm{Hr}, \mathrm{h}}\end{array}$} \\
\hline i. Lr,lh $+\ldots$ & $* !$ & \\
\hline ii. Lr,h $+\ldots$ & & $*$ \\
\hline
\end{tabular}

In (5a), candidate (5ai) incurs no violations because the tone is in isolation and therefore phrasefinal. In contrast, candidate (5aii) returns a tone contour that is not identical to the input, violating IDENT[T]. Thus in (5a), sandhi does not apply even though $/ \mathrm{Hr}, \mathrm{hl} / \mathrm{has}$ a contour tone. In $(5 \mathrm{~b}, \mathrm{c})$, *NON-FCTR overrides faithfulness requirements to produce a flat tone for syllables that are followed by some other material. Candidates (5bi) and (5ci) both have contoured tone melodies in non-final positions. As such, candidates (5bii) and (5cii) are preferred for their respective inputs. *NoN-FCTR, however, does not produce the chain shift; what it does would cause neutralisation between the pairs $/ \mathrm{Hr}, \mathrm{hl} / \mathrm{and} / \mathrm{Hr}, \mathrm{h} /$, and $/ \mathrm{Lr} . \mathrm{lh} /$ and $/ \mathrm{Lr}, \mathrm{h} /$.

Barrie's (2006) insight is that pressures from PRESERVE CONTRAST (Łubowicz 2003, 2012) are what engender chain reactions in the face of neutralisation in Taiwanese Min. I adopt this in the form of a constraint in (6). 


\section{$\mathrm{P}$ (reserve) $\mathrm{C}$ (ontrast)}

Assign one violation mark for every instance where, in the same morpho-phonological environment, an output is not distinct from that of a different input.

Following the effects of (5), $\mathrm{PC}$ ensures that non-final $/ \mathrm{Hr}, \mathrm{h} /$ must undergo alternation. The same would apply to non-final $/ \mathrm{Lr}, \mathrm{h} /$. Crucially, in (7a-c) below, each is a successive step that follows (5) as PC unfolds over time in reaction to the neutralisation effects of (5).

Chain reactions with $\mathrm{PC}$

\begin{tabular}{|c|c|c|c|}
\hline $\begin{array}{l}\text { a. } 1^{\text {st }} \text { link in chain reaction } \\
\text { input: } \mathrm{Hr}, \mathrm{h}+\ldots \\
\text { cf. } / \mathrm{Hr}, \mathrm{hl} / \rightarrow[\mathrm{Hr}, \mathrm{h}] / \ldots \ldots\end{array}$ & $\mathrm{PC}$ & *NON-FCTR & IDENT[T] \\
\hline i. $\mathrm{Hr}, \mathrm{h}+\ldots$ & $*_{/ \mathrm{Hr}, \mathrm{hl} / !}$ & & \\
\hline ii. $\mathrm{Hr}, \mathrm{hl}+\ldots$ & & $* !$ & $*$ \\
\hline iii. Lr,h+... & & & $*$ \\
\hline iv. $\mathrm{Lr}, \mathrm{hl}+\ldots$ & & $* !$ & $*$ \\
\hline \multicolumn{4}{|l|}{$\begin{array}{l}\text { b. } 2^{\text {nd }} \text { link in chain reaction } \\
\text { input: } \mathrm{Lr}, \mathrm{h}+\ldots \\
\text { cf. } / \mathrm{Hr}, \mathrm{h} / \rightarrow[\mathrm{Lr}, \mathrm{h}] / \quad \ldots\end{array}$} \\
\hline i. $\mathrm{Lr}, \mathrm{h}+\ldots$ & $*_{/ \mathrm{Hr}, \mathrm{h} / !}$ & & \\
\hline ii. Lr,hl $+\ldots$ & & * & $*$ \\
\hline iii. $\mathrm{Hr}, \mathrm{h}+\ldots$ & $*_{/ \mathrm{Hr}, \mathrm{hl} / !}$ & & $*$ \\
\hline iv. $\mathrm{Hr}, \mathrm{hl}+\ldots$ & & $*$ & $* * !$ \\
\hline \multicolumn{4}{|l|}{$\begin{array}{l}\text { c. } 3^{\text {rd }} \text { link in chain reaction } \\
\text { input: } \mathrm{Lr}, \mathrm{hl}+\ldots \\
\text { cf. } / \mathrm{Lr}, \mathrm{h} / \rightarrow[\mathrm{Lr}, \mathrm{hl}] / \ldots \ldots\end{array}$} \\
\hline i. $\mathrm{Lr}, \mathrm{h}+\ldots$ & $*_{/ \mathrm{Hr}, \mathrm{h} / !}$ & & * \\
\hline ii. $\mathrm{Lr}, \mathrm{hl}+\ldots$ & $*_{/ \mathrm{Lr}, \mathrm{h} / !}$ & $*$ & \\
\hline iii. $\mathrm{Hr}, \mathrm{h}+\ldots$ & $*_{/ \mathrm{Hr}, \mathrm{hl} / !}$ & & $* *$ \\
\hline iv. Hr,hl $+\ldots$ & & $*$ & $* *$ \\
\hline
\end{tabular}

The way PC works in (7) is diachronic and hence crucially link-dependent. In (7a), PC only has access to the output of (5) and has no foresight to the ensuing chain effects. Similarly, (7b) only has access to (5) and (7a), while (7c) will have access to all the precedent outputs. Having no foresight is necessarily the case in all viable diachronic accounts unless one has a crystal ball that looks into the future.

The case in (7c) involving the input /Lr,hl/ is tricky. Here, one might have expected *NoNFCTR to intervene and create a flat tone. However, the high-ranking PC would ensure that there will be no other choice but to circle back on $/ \mathrm{Hr}, \mathrm{hl} /$. For this solution to work, it is necessary that, diachronically, sandhi of $/ \mathrm{Hr}, \mathrm{hl} / \rightarrow[\mathrm{Hr}, \mathrm{h}]$ emerged before sandhi of $/ \mathrm{Lr}, \mathrm{hl} /{ }^{6}$

While the sandhi circle is now within grasp, there is one final complication from $/ \mathrm{Lr}, \mathrm{lh} / \rightarrow$ [Lr,h]. This is a direct threat to a PC account because contrast preservation is clearly lost when both $/ \mathrm{Hr}, \mathrm{h} /$ and $/ \mathrm{Lr}, \mathrm{lh} /$ neutralise to $[\mathrm{Lr}, \mathrm{h}]$. As a rising tone, $/ \mathrm{Lr}, \mathrm{h} /$ is perhaps the most marked

\footnotetext{
${ }^{6} \mathrm{Had} / \mathrm{Lr}$,hl/ succumbed to non-final flattening first to yield [Lr,h], the whole Taiwanese sandhi chain would have had a very different outlook. PC would spin the arrows differently.
} 
in the tone inventory of Taiwanese Min. This was also noted by Barrie (2006), Thomas (2008), and Hsiao (2015) when they appealed to a more specific markedness constraint such as (8).

*NON-FR

Assign one violating mark for every non-final rising tone.

Deriving the sandhi circle appendix

\begin{tabular}{|c||c|c|c|c|}
\hline input: $\mathrm{Lr}, \mathrm{lh}+\ldots$ & *NON-FR & PC & *NON-FCTR & IDENT[T] \\
\hline \hline i. $\mathrm{Hr}, \mathrm{h}+\ldots$ & & $*_{/ \mathrm{Hr}, \mathrm{hl} /}$ & & $* * !$ \\
\hline ii. $\mathrm{Hr}, \mathrm{hl}+\ldots$ & & $*_{/ \mathrm{Lr}, \mathrm{hl} /}$ & $* !$ & $* *$ \\
\hline iii. $\mathrm{Lr}, \mathrm{h}+\ldots$ & & $*_{/ \mathrm{Hr}, \mathrm{h} /}$ & & $*$ \\
\hline iv. $\mathrm{Lr}, \mathrm{hl}+\ldots$ & & $*_{\mathrm{Lr}, \mathrm{h} /}$ & $* !$ & $*$ \\
\hline v. $\mathrm{Lr}, \mathrm{hh}+\ldots$ & $* !$ & & $*$ & \\
\hline
\end{tabular}

As may be seen in the tableau in (9), when *NoN-FR outranks PC, the consequence is this neutralisation nonetheless, and it is the unmarked flat melody that emerges. With this, the tone circle in (1c) is complete. However, this is only a diachronic account that assumed sandhi applied first to non-final $/ \mathrm{Hr}, \mathrm{hl} /$ before the pressures of PC set in to yield a chain. This is why (7) did not include a tableau for $/ \mathrm{Hr}, \mathrm{hl}+\ldots .^{7}$

\subsection{Settling on the modern grammar}

To modern speakers, the diachronic shifts engendered by PC in reaction to the avoidance of non-final contour tones are complete and irrelevant. Their internalised grammar would come only from the data that is presented to them during the process of acquisition. Thus, for them, the mapping in (1c) is a fait accompli as they map the two surface forms (citation and sandhied form) of the same morph to some underlying representation. In fact, for the modern speaker, *NON-FCTR would probably rank low since contour tones are found in abundance as the sandhi circle ensures that contour melodies surface in non-final positions as well. For the purposes of this paper, one does not have to be committed about where this constraint will figure in the ranking hierarchy of the modern speaker, but the logic remains. By the same reasoning, it is likely that $*$ NoN-FR remains active due to the fact that rising tones in final positions remain unattested in Taiwanese Min. For now, it seems reasonable to assume that PC continues to rank high since there is no a priori reason for its demotion. ${ }^{8}$

Something else, however, must come into play. I imagine that the modern speaker's grammar must ultimately be one where the pairings in (1c) are motivated by transderivational antifaithfulness (TAF, Alderete 1999) since the original impetus from markedness would have become mitigated by the abundance of contoured melodies in non-final positions. It is as though, because of PC, *NON-FCTR is defeated after all as the grammar evolves over time. Antifaithfulness is transderivational ${ }^{9}$ and in this case will require that non-final forms be not identical to the citation forms, as illustrated in (10).

\footnotetext{
${ }^{7}$ Thanks to a reviewer for this query. The account is that (5) happened first, then $(7 a, b, c)$ in that order. PC is therefore interpreted here as a constraint that landed a cascading tone shift in the non-final positions of Taiwanese Min that took place over time. For this reason, $(7 \mathrm{a}, \mathrm{b}, \mathrm{c})$ have increasing PC-violating candidates.

${ }^{8} \mathrm{I}$ am not committing here to assumptions about the initial ranking hierarchy (see various such possibilities in Tesar and Smolensky 2000, especially pp. 69-70 and 75-76) of the Taiwanese infant, but merely remarking that historical change in grammars can be modelled by re-ranking of constraints. See also Tesar (2014, especially Chapter 7) for output-driven learning.

${ }^{9}$ There is sometimes a tendency among less careful theorists to freely allow antifaithfulness to apply to inputoutput (I-O) relations as well. Antifaithfulness has to be transderivational (echoing transderivational faithfulness
} 
(10)

ANTIF

Assign one violation mark to any candidate which is identical in both register and contour melody to its corresponding citation output.

\begin{tabular}{|c|c|c|c|c|}
\hline $\begin{array}{l}\text { a. input: } \mathrm{Hr}, \mathrm{h}+\ldots \\
\text { cf. } / \mathrm{Hr}, \mathrm{h} / \rightarrow[\mathrm{Hr}, \mathrm{h}] /\end{array}$ & ANTIF & PC & IDENT[T] & *NON-FCTR \\
\hline i. $\mathrm{Hr}, \mathrm{h}+\ldots$ & $* !$ & $*_{/ \mathrm{Hr}, \mathrm{hl} /}$ & & \\
\hline ii. $\mathrm{Hr}, \mathrm{hl}+\ldots$ & & $*_{\text {/Lr,hl/ }}$ & $*$ & $* !$ \\
\hline iii. $\mathrm{Lr}, \mathrm{h}+\ldots$ & & $*_{/ \mathrm{Lr}, \mathrm{lh} /}$ & $*$ & \\
\hline iv. Lr,hl $+\ldots$ & & $*_{/ \mathrm{Lr}, \mathrm{h} /}$ & $*$ & $* !$ \\
\hline \multicolumn{5}{|l|}{$\begin{array}{l}\text { b. input: } \mathrm{Lr}, \mathrm{h}+\ldots \\
\text { cf. } / \mathrm{Lr}, \mathrm{h} / \rightarrow[\mathrm{Lr}, \mathrm{h}] /{ }^{\prime} \text { \#\# }\end{array}$} \\
\hline i. $\mathrm{Lr}, \mathrm{h}+\ldots$ & * & $*_{/ \mathrm{Hr}, \mathrm{h} /}$ & & \\
\hline ii. Lr,hl $+\ldots$ & & & $*$ & \\
\hline iii. $\mathrm{Hr}, \mathrm{h}+\ldots$ & & $*_{/ \mathrm{Hr}, \mathrm{hl} / !}$ & $*$ & \\
\hline iv. $\mathrm{Hr}, \mathrm{hl}+\ldots$ & & $*_{/ \mathrm{Lr}, \mathrm{hl} / !}$ & $* *$ & $*$ \\
\hline \multicolumn{5}{|l|}{$\begin{array}{l}\text { c. input: } \mathrm{Lr}, \mathrm{hl}+\ldots \\
\text { cf. } / \mathrm{Lr}, \mathrm{hl} / \rightarrow[\mathrm{Lr}, \mathrm{hl}] /\end{array}$} \\
\hline i. $\mathrm{Lr}, \mathrm{h}+\ldots$ & & $*_{/ \mathrm{Hr}, \mathrm{h} / !}$ & * & \\
\hline ii. $\mathrm{Lr}, \mathrm{hl}+\ldots$ & $* !$ & $*_{/ \mathrm{Lr}, \mathrm{h} /}$ & & $*$ \\
\hline iii. $\mathrm{Hr}, \mathrm{h}+\ldots$ & & $*_{/ \mathrm{Hr}, \mathrm{hl} / !}$ & $* *$ & \\
\hline iv. $\mathrm{Hr}, \mathrm{hl}+\ldots$ & & & $* *$ & $*$ \\
\hline \multicolumn{5}{|l|}{$\begin{array}{l}\text { d. input: } \mathrm{Hr}, \mathrm{hl}+\ldots \\
\text { cf. } / \mathrm{Hr}, \mathrm{hl} / \rightarrow[\mathrm{Hr}, \mathrm{hl}] /\end{array}$} \\
\hline i. $\mathrm{Lr}, \mathrm{h}+\ldots$ & & $*_{/ \mathrm{Hr}, \mathrm{h} /}$ & * & \\
\hline ii. $\mathrm{Lr}, \mathrm{hl}+\ldots$ & & $*_{/ \mathrm{Lr}, \mathrm{h} / !}$ & $*$ & $*$ \\
\hline iii. $\mathrm{Hr}, \mathrm{h}+\ldots$ & & & $*$ & \\
\hline \multirow[t]{2}{*}{ iv. $\mathrm{Hr}, \mathrm{hl}+\ldots$} & $* !$ & $*_{/ \mathrm{Lr}, \mathrm{hl} /}$ & $*$ & $*$ \\
\hline & & & & \\
\hline \multicolumn{5}{|l|}{$\begin{array}{l}\text { e. input: } \mathrm{Lr}, \mathrm{lh}+\ldots \\
\text { cf. } / \mathrm{Lr}, \mathrm{lh} / \rightarrow[\mathrm{Lr}, \mathrm{lh}] /\end{array}$} \\
\hline i. $\mathrm{Hr}, \mathrm{h}+\ldots$ & & $*_{/ \mathrm{Hr}, \mathrm{hl} /}$ & $* * !$ & \\
\hline ii. $\mathrm{Hr}, \mathrm{hl}+\ldots$ & & $*_{\text {/Lr,hl/ }}$ & $* * !$ & $*$ \\
\hline iii. $\mathrm{Lr}, \mathrm{h}+\ldots$ & & $*_{/ \mathrm{Hr}, \mathrm{h} /}$ & $*$ & \\
\hline iv. $\mathrm{Lr}, \mathrm{hl}+\ldots$ & & $*_{/ \mathrm{Lr}, \mathrm{h} /}$ & $*$ & $* !$ \\
\hline v. Lr,lh $+\ldots$ & $* !$ & & & $*$ \\
\hline
\end{tabular}

In (10), the ANTIF constraint is defined with respect to the citation output forms of the tone, so the antifaithfulness relation is between the sandhied forms, which are non-final, and the citation forms, which occur in isolation or in phrase-final positions. Such a description matches most closely the realities of the linguistic environment of the modern Taiwanese Min speaker who will hear the same monomorphemic syllable ${ }^{10}$ in two different tones depending on their

\footnotetext{
- Benua 1997) or at least never applying between I-O mappings. This is because there is otherwise no coherent argument for the postulation of an underlying form. Careful argumentation can be found in Alderete (1999).

${ }^{10}$ All syllables are morphemic in Chinese with very few, even if qualified, exceptions.
} 
morphosyntactic positions. In (10), ANTIF punishes any candidate that is identical to its citation form, as in candidates (10ai, bi, cii, div, and ev).

To the modern speaker, PC will be sensitive to all outputs, unlike (7) where change was in progress. For (10a) and (10e) then, all candidates will incur a violation of PC because all forms correspond to some other input form that produces them in non-final positions. For (10b-d), however, there is always one candidate that satisfies PC since that form is derived only from one particular input. I have omitted [Lr,lh] as a candidate for $(10 \mathrm{a}-\mathrm{d})$, which is presumably ruled out by *NoN-FR.

The grammar for a modern speaker of Taiwanese Min is therefore rather straightforward, resulting from a combination of contrast preservation and antifaithfulness. These are rather special devices, but certainly not contrived since they have independently been established. In fact, one would be puzzled if there were no language phenomena where the two come together as they do in Taiwanese Min.

\subsection{An unexpected corroboration: Poverty in productivity}

A seemingly inelegant feature of the analysis in (10) is the high number of violations of highranking constraints, making the optimal candidate a rather precarious choice. This precariousness finds an unexpected corroboration in the controversy between the works of Zhang and Lai (2008) and Zhang, Lai and Sailor (2011), one the one hand, and the results of Chuang, Chang and Hsieh (2011) on the other.

Sceptical of the productivity of the tone circle in (1c), Zhang and his colleagues devised a clever experiment modelled on the Wug test (Berko 1958). Three different types of stimuli were used to engage speakers in reduplication. Since reduplication would create a non-final context for each stimulus, the productivity of tone sandhi may be determined. The three types of stimuli included actual occurring forms ("AO" in Zhang's parlance), attested syllables that are not reduplicated $(* \mathrm{AO})$, and unattested syllables that conform to Taiwanese Min phonotactics (AG). The results were that AO syllables induced sandhi as expected. *AO syllables, however, did slightly worse but induced sandhi generally nonetheless. AG syllables appear to have the worst sandhi rates, scoring only slightly better than chance level. Zhang et al. (2011) extrapolated from the results that the Min tone sandhi is perhaps not productive after all, and the challenge posed to phonological theorising is diffused.

Unconvinced, Chuang et al. (2011) devised a different experiment where subjects are presented with nonce non-final syllables. Elicitation is then made for those syllables in phrase-final/isolated positions. Interestingly, the subjects "back-constructed" and produced the corresponding citation tones to a high degree of consistency, as if working the circle in (1c) backwards for tone retrieval. If indeed tone sandhi is not productive as Zhang et al. (2011) claimed, back-construction would be impossible when presented with nonce forms, and only in non-final positions.

Both camps - Zhang et al. (2011) and Chuang et al. (2011) - appear to me impeccable in their methodologies, and the results can be easily reduplicated by anyone who is doubtful. I do, however, find Zhang et al.'s (2011) conclusions somewhat hasty. First is the possibility that nonce words are simply processed as foreign and hence are not subject to the same grammar. This is not new as has been observed since the early days of Chomsky and Halle's (1968) The Sound Pattern of English where features like [latinate] would tease out morpho-phonology that applies differently from English items that have a Romance history (see Chomsky and Halle 
(1968: 373) and Mohanan (1986: 127) for Malayalam words that have Sanskrit origins). It is unclear how the mind can acquire such patterns without access to history, but it is possible that relevant lexical items may have been marked by cues of stress placement or other phonotactic properties. With Taiwanese, the nonce items *AO and AG that Zhang et al. (2011) used may have been mentally processed as foreign. Further, Zhang et al.'s (2011) findings were that sandhi applies more for *AO than for AG. It does seem, therefore, that it is the degree of uncanniness that is preventing sandhi application.

The controversy between Zhang's and Chuang's camps finds an easy resolution in (10). Given the rampant high-ranking violations, one would expect the sandhied forms to be treated as marked in the mental grammar of the modern speaker, even if they did surface as optimal in non-final positions. It would therefore be unsurprising that these sandhied forms may be disfavoured, which can only be done by not applying sandhi, in opportune situations such as when uttering nonce forms. The grammar is nonetheless active, which would explain why Chuang's subjects remain able in back-construction.

\section{4. $\quad$ Precedent shoulders}

While further corroborative evidence is needed for the viability of the analysis given in section 3 , it is probably by far the only one that explains how the sandhi circle came to be and how it remains a part of the modern speakers' grammar. Although often mentioned, the Taiwanese Min sandhi circle has rarely been directly tackled for the theoretical challenges it poses. To the best of my knowledge, only Horwood (1999), Wee (2002), Barrie (2006), Thomas (2008), and Hsiao (2015) have tried to charm this snake. ${ }^{11}$

\subsection{The fall of the antifaithful}

Horwood (2000) ${ }^{12}$ and Wee (2002) tried to address the challenge with transderivational antifaithfulness. Horwood (2000) noted that the tone circle involved either a change in register or contour but never both.

(11) Examples of antifaithful transderivational correspondence
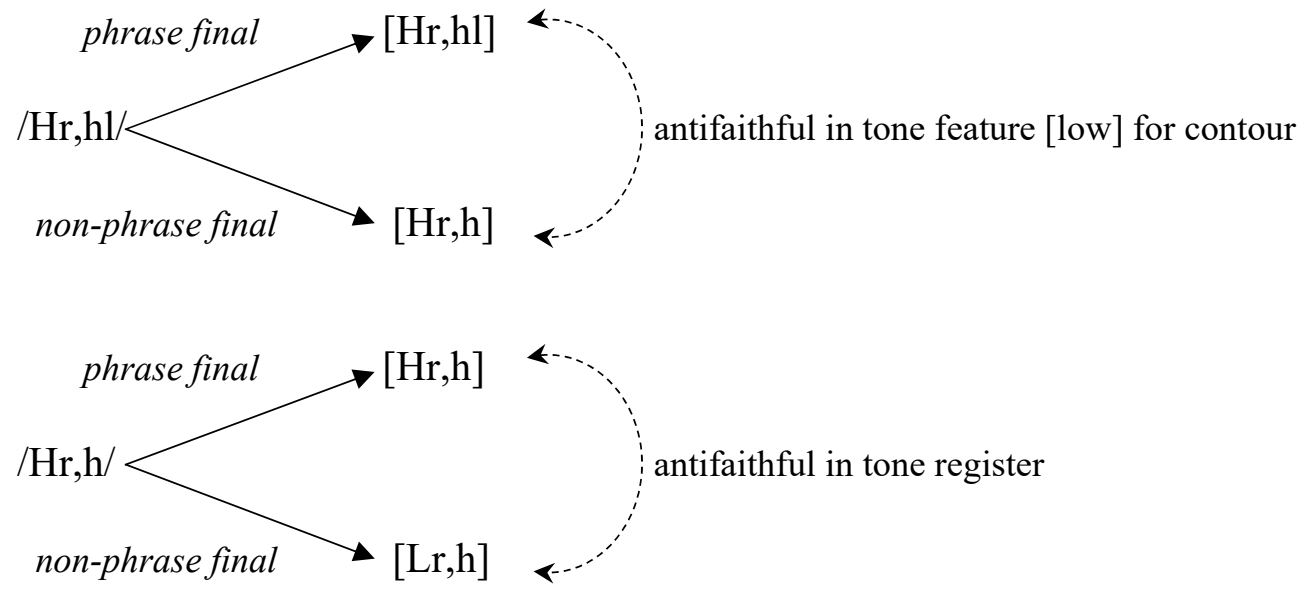

\footnotetext{
${ }^{11}$ To take this bull by its horns may be the right idiom, but it is the Ouroboros in this case.

${ }^{12}$ Which took place at Rutgers when this author was a graduate student. The seminar might have been part of Akin's class (or Hubert Truckenbrodt's), but I am not too sure now after nearly two decades.
} 
In OT terms, this could lead to a constraint-ranking paradox because both ANTIF » IDENT[contour] and ANTIF »IDENT[register] must be true to accommodate the two cases in (12). At the same time IDENT[register] " ANTIF to avoid register change for cases like $/ \mathrm{Hr}, \mathrm{hl} / \rightarrow[\mathrm{Hr}, \mathrm{h}]$; similarly IDENT[contour] » ANTIF for cases like $/ \mathrm{Hr}, \mathrm{h} / \rightarrow[\mathrm{Lr}, \mathrm{h}]$.

Wee (2002) built upon this insight through constraint conjunction to prioritise the conjoined constraint IDENT[register\&contour] over ANTIF to ensure that effect. His analysis appealed to a ranking IDENT[register\&contour] » ANTIF » IDENT[register], IDENT[contour], which ensures alternation only in satisfaction of antifaithfulness but never targeting both register and contour at the same time.

(12) Failure of Wee (2002)

IDENT-Register (ID-R)

Assign a violation mark for every register specification in the input that is changed in the output.

IDENT-Contour (ID-C)

Assign a violation mark for every contour specification in the input that is changed in the output.

ID-R\&C

Assign a violation mark for every output tone that violates both ID-R and ID-C.

\begin{tabular}{|c||c|c|c|c|c|}
\hline a. input: $/ \mathrm{Lr}, \mathrm{h}+\ldots /$ & ID-R\&C & ANTIF & NON-FR & ID-C & ID-R \\
\hline \hline i. Lr,h & & $* !$ & & & \\
\hline ii. Lr,hl & & $*$ & & $*$ & \\
\hline iii. Hr,hl & $* !$ & & & $*$ & $*$ \\
\hline iv. Hr,h & & & & & $*$ \\
\hline v. Lr,h & & $*$ & $* !$ & $*$ & \\
\hline \hline b. input: $/ \mathrm{Hr}, \mathrm{h}+\ldots /$ & & & & & \\
\hline \hline i. Lr,h & & $*$ & & & $*$ \\
\hline ii. Lr,hl & $* !$ & & & $* !$ & $*$ \\
\hline iii. Hr,hl & & $*$ & & $*$ & \\
\hline iv. Hr,h & & $* * !$ & & & \\
\hline v. Lr,h & & $*$ & $* !$ & $*$ & \\
\hline
\end{tabular}

As may be seen in (12), Wee (2002) defined the IDENT constraints separately for tone register and contour, and invoked a conjoined constraint, ID-R\&C. While Wee is able to get either only the register or the contour to alternate, he is unable to predict correctly the clockwise spin of the tone circle in (1c). If either register or contour may alternate, then the Horwood-Wee analysis allows $\mathrm{Hr}, \mathrm{h} \rightarrow \mathrm{Hr}$,hl as either a free variation to the input $/ \mathrm{Hr}, \mathrm{h} /$ (i.e. 12biii) or there should be a dialect of Taiwanese/Xiamen where the tone circle is anti-clockwise of (1c). Neither have been known to be attested.

\subsection{Missing the point even with $\mathrm{PC}$ and antifaithfulness}

Barrie (2006), as noted before, was the first to argue for the power of PC to capture the Taiwanese Min tone circle. The idea is straightforward: if $/ A / \rightarrow[B]$, then $/ B / \rightarrow *[B]$ because $/ \mathrm{A} /$ and $/ \mathrm{B} /$ both mapping to $[\mathrm{B}]$ means that the contrast is neutralised. PC resists such neutralisation. If the set of derived forms cannot be different from the underlying inventory, 
PC would yield a circle rather than a linear chain. Obviously PC cannot be undominated in Taiwanese/Xiamen since $/ \mathrm{Lr}, \mathrm{lh} /$ and $/ \mathrm{Hr}, \mathrm{h} /$ both neutralise to [Lr,h] when sandhied. This is resolved by undominated *RISE which bans rising tones, adopted as *NON-FR in (9) above. It would be unfair to critique Barrie (2006) as incomplete because he mainly set out to argue (i) that the tone sandhi in Xiamen/Taiwanese is phonological (not morphological), and that (ii) an optimality theoretical solution is possible within PC where classical models might fall short. With that qualification, one should note that Hsiao's (2015) critique of Wee's (2002) spin direction also extends to Barrie (2006).

Thomas (2008) offers another attempt, evoking a cocktail of antifaithfulness (termed "DIFFER" in his paper) and PC (which he called "*MERGE" to prevent neutralisation). These are the same ingredients used for the analysis in section 3 of this paper, but with some crucial differences that prevented Thomas's (2008) account from being successful.

Instead of appealing to an architecture of tone that contains register and contour, Thomas worked with the tone values described using Chao's (1930) system, calculating faithfulness violations in terms of difference in pitch using the tone values as units of measurement (akin but not identical to register) and in terms of identity of contour shape between citation and sandhied tones. Thomas's approach is predicated on the accuracy of the tone values (ranging from 1 to 5), but there is no evidence that Xiamen (or Taiwanese) actually distinguishes between so many levels of pitch height. The tone values he cited are drawn exclusively from Chen (1987), but a look into the first-hand data of a dialectological survey would quickly show that such tone values are really only accurate for range (register) and shape (contour). They cannot be interpreted as exact (see (2a), for example, where Yuan (1956) described the sandhied form of [55] and [24] as [33] or perhaps a bit higher, like [44], hence the presentation $[33 / 44]) .{ }^{13}$ Thomas's account, like those before him, fell short of the clockwise spin in (1c). This is because, for him, both ANTIF and PC did the same work, even though PC set off the spin triggered by *NON-FR (or "*RISE" in his parlance), and ANTIF put the brakes on so that each sandhi application stopped only at the next station.

In comparison, the account given in section 3 above is very similar to those of Barrie (2006) and Thomas (2008) in terms of the constraints used. However, there are a number of differences. Firstly, my paper postulates that the trigger was a ban on non-final contours, specifically $/ \mathrm{Hr}, \mathrm{hl} /$ being the first target of alternation, not a ban on final rising tones. This difference is important because it would actually set the spin direction where Barrie's (2006) and Thomas's (2008) did not. Secondly, this account distinguishes between the diachronic processes that produce the sandhi circle from the synchronic grammar of the modern speaker. In so doing, ANTIF becomes the force ensuring alternation while PC continues to provide the historical basis for the sandhi. Empirically, therefore, this account actually considers all the relevant candidates and correctly selects the optima for all the inputs while also providing an account for how the patterns are likely to have arisen diachronically.

\subsection{An approach through comparativity}

Hsiao (2015) offers an analysis that is based on comparative markedness (McCarthy 2003). One of the major strengths of Hsiao's paper was the insightful observation that precedent works (i.e. Horwood 2000, Wee 2002, Barrie 2006, and Thomas 2008) have all failed to rule out a sandhi pattern for Taiwanese Min where the arrows in (1c) are reversed. The key idea in comparative

\footnotetext{
${ }^{13}$ Yuan uses Middle Chinese categories stating, for example, that "Yin Ping [55] and Yang Ping [24] sandhi to
} Yang Qu [33] slightly higher" (my translation). 
markedness is the distinction in status between what is derived and what is underived. Thus, conceivably, the same form F may be considered more or less marked depending on whether or not $\mathrm{F}$ is the result of some (phonological) operation. Under comparative markedness, [Hr,hl] can be less marked if derived from $/ \mathrm{Lr}, \mathrm{hl} /$ or $/ \mathrm{Hr}, \mathrm{h} /$ than $/ \mathrm{Hr}, \mathrm{hl} /$, if MARKEDNESSunDERIVED » FAITHFULNESS » MARKEDNESSDERIVED. This would provide the necessary brakes in the chain shift and avoid non-convergence (i.e. achieve derived idempotency).

In order for a markedness constraint to apply to all the input tones, Hsiao proposed the constraints in (13).

(13) Taiwanese sandhi trigger (Hsiao 2015)

a. $\quad *_{\mathrm{o}} \mathrm{T}_{\mathrm{i}}\left(\mathrm{CAND}, \mathrm{FFC}, \mathfrak{R}_{\mathrm{t}}\right)$ : Let $\mathrm{LOC}_{\mathrm{i}}(\mathrm{CAND})=\left\{\mathrm{c}_{1}, \mathrm{c}_{2}, \mathrm{c}_{3}, \ldots\right\}$ and let $\mathrm{LOC}_{\mathrm{i}}(\mathrm{FFC})=$ $\left\{\mathrm{f}_{1}, \mathrm{f}_{2}, \mathrm{f}_{3}, \ldots\right\}$. For each $\mathrm{T}_{\mathrm{m}}$ that has a $\mathrm{t}$-correspondent among $\mathrm{f}_{\mathrm{n}}$, assign one violation mark.

b. $\quad *_{\mathrm{N}} \mathrm{T}_{\mathrm{i}}\left(\mathrm{CAND}, \mathrm{FFC}, \mathfrak{R}_{\mathrm{t}}\right)$ : Let $\operatorname{LOC}(\mathrm{CAND})=\left\{\mathrm{c}_{1}, \mathrm{c}_{2}, \mathrm{c}_{3}, \ldots\right\}$ and let $\mathrm{LOC}_{\mathrm{i}}(\mathrm{FFC})=$ $\left\{\mathrm{f}_{1}, \mathrm{f}_{2}, \mathrm{f}_{3}, \ldots\right\}$. For each $\mathrm{T}_{\mathrm{m}}$ that lacks a t-correspondent among $\mathrm{f}_{\mathrm{n}}$, assign one violation mark.

, where $\mathrm{o} T=$ underived tone; ${ }_{\mathrm{N}} \mathrm{T}=$ derived tone; $\mathrm{CAND}=$ candidate; $\mathrm{FFC}=$ fully faithful candidate

I have retained Hsiao's original formulation ${ }^{14}$ of his constraints in (13) so that it would not be misrepresented. In essence, (13) is a pair of constraints where each requires an output candidate to have a different tone from the input. By studying the constraints, one will notice that (13) penalises a fully faithful candidate (FFC) mapped directly from the input to the output. The difference between (13a) and (13b) is that the former applies to underived tonal inputs $\left({ }_{0} T_{i}\right)$ and the latter to derived tonal inputs $\left({ }_{N} T_{i}\right)$. With (13a) and (13b), Hsiao certainly makes a distinction between derived and underived forms (hence comparative). However, ${ }^{*} \mathrm{~T}_{\mathrm{i}}\left(\mathrm{CAND}, \mathrm{FFC}, \mathfrak{R}_{\mathrm{t}}\right)$ and ${ }_{\mathrm{N}} \mathrm{T}_{\mathrm{i}}\left(\mathrm{CAND}, \mathrm{FFC}, \mathfrak{R}_{\mathrm{t}}\right)$ are antifaithful in essence. Hsiao's approach is therefore, in spirit, "comparative antifaithfulness". If indeed so, one can dispense with (13b). To qualify as markedness, Hsiao's constraints must be interpreted as families so that $*_{\mathrm{N}} \mathrm{T}_{\mathrm{i}}$, for instance, refers to a set that comprises at least $*_{\mathrm{N}}[\mathrm{Hr}, \mathrm{h}],{ }_{\mathrm{N}}[\mathrm{Lr}, \mathrm{h}],{ }_{\mathrm{N}}[\mathrm{Lr}, \mathrm{hl}]$ and $*_{\mathrm{N}}[\mathrm{Hr}, \mathrm{hl}]$, each a separate constraint.

Like Wee (2002), Hsiao's comparative constraints do not address the spin direction in (1c); they merely ensure that sandhi stops at each station of the circuit. To get the direction of the spin, Hsiao appeals to constraint conjunction, conjoining ${ }_{N} T_{i}\left(C A N D, F F C, \mathfrak{R}_{t}\right)$ with faithfulness. This is illustrated in (14), where [Hr,hl] is shown to be derived from / $\mathrm{Lr}, \mathrm{hl} /$ and not from $/ \mathrm{Lr}, \mathrm{h} /$.

\footnotetext{
${ }^{14}$ Hsiao did not state explicitly the intended interpretations of $\mathfrak{R}_{\mathrm{t}}$ and LOC. When unpacked, I believe $\mathfrak{R}_{\mathrm{t}}$ to refer to a relation between CAND and FFC, while LOC is used for distinguishing between final and non-final positions. Thus. $\mathrm{LOC}_{\mathrm{i}}(\mathrm{CAND})$ maps CAND to possible tones in non-final positions where sandhi is expected, and $\mathrm{LOC}_{\mathrm{i}}(\mathrm{FFC})$ maps FFCs to final positions. This is why ${ }^{*} \mathrm{~T}_{\mathrm{i}}$ would penalise in accordance with tone correspondences with items in the set defined by $\operatorname{LOC}_{\mathrm{i}}(\mathrm{FFC})=\left\{\mathrm{f}_{1}, \mathrm{f}_{2}, \mathrm{f}_{3}, \ldots\right\}$.
} 
(14) Hsiao's (2015) constraint conjunctions

$*_{\mathrm{N}}[\mathrm{Hr}, \mathrm{h}] \& \mathrm{ID}-\mathrm{R}$

Assign a violation mark for every output tone that violates both $*_{N}[\mathrm{Hr}, \mathrm{h}]$ and ID-R.

$*_{\mathrm{N}}[\mathrm{Lr}, \mathrm{h}] \& \mathrm{ID}-\mathrm{C}$

Assign a violation mark for every output tone that violates both $*_{\mathrm{N}}[\mathrm{Lr}, \mathrm{h}]$ and ID-C.

\begin{tabular}{|c|c|c|c|c|c|c|c|c|}
\hline a. input: & $* \mathrm{~T}$ & In $P$ & $\mathrm{ID}_{-} \mathrm{C}$ & $* \mathrm{~T}$ & *NOLP & ID- & $:{ }_{\mathrm{N}}[\mathrm{Hr}, \mathrm{h}]$ & ${ }_{N}[L r, h] \&$ \\
\hline$/ \mathrm{Lr}, \mathrm{h}+\ldots /$ & 01 & ID-K & :ID-C & $\mathrm{N} I$ & "NON-FK & $\mathrm{R} \& \mathrm{C}$ & ID-R & ID-C \\
\hline i. Lr,lh & & & $*$ & $*$ & $* !$ & & & \\
\hline ii. Lr,h & $* !$ & & & & & & & \\
\hline iii. Lr,hl & & & $*$ & $*$ & & & & \\
\hline iv. Hr,hl & & $*$ & $* !$ & * & & $*$ & & \\
\hline v. $\mathrm{Hr}, \mathrm{h}$ & & $*$ & & $*$ & & & $* !$ & \\
\hline & & & & & & & & \\
\hline $\begin{array}{l}\text { b. input: } \\
\text { /Lr,hl + ... }\end{array}$ & & & & & & & & \\
\hline i. Lr,lh & & & $*$ & * & $* !$ & & 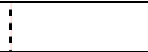 & \\
\hline ii. Lr,h & & & $*$ & $*$ & & & $i$ & $* !$ \\
\hline iii. Lr,hl & $* !$ & & & & & & & \\
\hline iv. $\mathrm{Hr}, \mathrm{hl}$ & & $*$ & & $*$ & & & & \\
\hline v. $\mathrm{Hr}, \mathrm{h}$ & & * & $* !$ & * & & * & & \\
\hline
\end{tabular}

In Hsiao's original presentation as given above, the left-half of the tableau explains what rules out the maximally faithful candidate through ${ }_{\mathrm{O}} \mathrm{T}$ (which we have seen is in reality ANTIF from the way it is defined). The right-half of the tableau is what concerns us here, where it can be seen that the conjoined constraint $*_{\mathrm{N}}[\mathrm{Hr}, \mathrm{h}] \&$ ID-R militates against candidate (14av), thus preventing an anti-spin of (1c). The same applies to how $*_{N}[\mathrm{Lr}, \mathrm{h}] \& \mathrm{ID}-\mathrm{C}$ penalises candidate (14bii).

To be empirically complete, Hsiao's approach will require each markedness constraint under $*_{\mathrm{N}} \mathrm{T}_{\mathrm{i}}\left(\mathrm{CAND}, \mathrm{FFC}, \mathfrak{R}_{\mathrm{t}}\right.$ ) to be conjoined with some faithfulness constraint. Specifically, Hsiao will need $*_{\mathrm{N}}[\mathrm{Lr}, \mathrm{hl}] \& \mathrm{ID}-\mathrm{R}$ and $*_{\mathrm{N}}[\mathrm{Hr}, \mathrm{hl}] \& \mathrm{ID}-\mathrm{C}$. Questions that immediately arise against Hsiao's analysis relate to factorial typology. Essentially, the analysis requires at least a pair of markedness constraints (derived and underived) specific to each tone and a stipulated conjunction between only the derived markedness constraint with either ID-R or ID-C. With three distinct constraints per sandhi rule, the analysis appears to be very contrived, and stipulates more than it explains. A single stipulative rule for each sandhi would have been simpler. In comparison, the analysis provided in section 3 uses only the same set of constraints for all the input tones.

The point of the review in this section is to highlight the areas that precedent analyses provided as stepping stones for the present paper. This paper imbibes antifaithfulness from Horwood (2000) and Wee (2002), PC from Barrie (2006) and Thomas (2008), and the explicit challenge of getting the spin direction right from Hsiao (2015). 


\section{Conclusion}

This paper looked into the circular chain shifts of the Taiwanese Min tone circle and proposed a cocktail solution that involves (i) a diachronic response of contrast preservation in response to the neutralising effects of markedness settling on (ii) a modern grammar that interprets the historical artefact as antifaithfulness. Herein lies a prediction that awaits corroboration in historical linguistic studies. Archaic documents may be hard to find but these may be a direction for future research. Another place to find corroborative evidence would be in the acquisition of sandhi rules in Taiwanese and Xiamen. The account presented here, if correct, would predict $/ \mathrm{Hr}, \mathrm{hl} / \rightarrow[\mathrm{Hr}, \mathrm{h}]$ to be acquired before the other three in the circle. These hypotheses await future research.

With respect to a general understanding of chain shifts, this paper's claim is more modest. The very approach it has taken suggests that chain-shifting may be a surface phenomenon that has different causes. Logically, PC, antifaithfulness, and comparative markedness can each be a cause of chain-shifting effects. Taiwanese Min, as analysed here, is complex in that it involves both PC and antifaithfulness, but there is no a priori reason to believe that this has to be a general solution to all cases of chain shifts, not even to its sister Southern Min languages such as Hainan and Teochew.

\section{References}

Alderete, J. 1999. Morphologically Governed Accent in Optimality Theory. Unpublished PhD dissertation, University of Massachusetts.

Bao, Z. 1999. The structure of tone. Oxford: Oxford University Press.

Barrie, M. 2006. Tone circles and contrast preservation. Linguistic Inquiry 37(1): 131-141. https://doi.org/10.1162/002438906775321148

Benua, L. 1997. Transderivational Identity: Phonological Relations between Words. Unpublished $\mathrm{PhD}$ dissertation, University of Massachusetts.

Berko, J. 1958. The child's learning of English morphology. Word 14(2-3): 150-177. https://doi.org/10.1080/00437956.1958.11659661

Cai, J. 1991. Chaozhou fangyan cihui ['A dictionary of Chaozhou dialect']. Hong Kong: Institute of Chinese Culture, Chinese University of Hong Kong.

Chao, Y.-R. 1930. A system of tone letters. La Maître Phonétique 30: 24-27.

Chen, M.Y. 1987. The syntax of Xiamen tone sandhi. Phonology Yearbook 4(1987): 109-149.

Chomsky, N. and M. Halle. 1968. The sound pattern of English. Cambridge, MA: The MIT Press.

Chuang, C., Y. Chang and F. Hsieh 2011. Productivity in Taiwanese tone sandhi Redux. Available online: https://www.internationalphoneticassociation.org/icphs-proceedings/ICPhS2 011/OnlineProceedings/RegularSession/Chuang,\%20Ching-ting/Chuang,\%20Ching-ting.pdf (Accessed 17 April 2017). 
Horwood, G. 1999. Anti-Identity and Taiwanese Tone Sandhi. Seminar handout, Rutgers University.

Hsiao, Y.E. 2015. Tonal chain shifts in Taiwanese: A comparative markedness approach. In Y.E. Hsiao and L.-H. Wee (eds.) Capturing phonological shades within and across languages. Newcastle upon Tyne: Cambridge Scholars Publishing. pp. 142-165.

Łubowicz, A. 2003. Contrast Preservation in Phonological Mapping. Unpublished PhD dissertation, University of Massachusetts.

Łubowicz, A. 2012. The phonology of contrast. Sheffield: Equinox.

McCarthy, J.J. 2003. Comparative markedness. Theoretical Linguistics 29(2): 1-51.

Mohanan, K.P. 1986. The theory of lexical phonology. Dordrecht: Reidel Publishing Company.

Myers, J. and J. Tsay. 2008. Neutralization in Taiwan Southern Min tone sandhi. In Y.E. Hsiao, H. Hsu, L.-H. Wee and D. Ho (eds.) Interfaces in Chinese phonology. Taipei: Institute of Linguistics, Academia Sinica. pp. 47-78.

Peng, S.-H. 1997. Production and perception of Taiwanese tones in different tonal and prosodic contexts. Journal of Phonetics 25(3): 371-400. https://doi.org/10.1006/jpho.1997.0047

Pulleyblank, E.G. 1984. Middle Chinese: A study in historical phonology. Vancouver: University of British Columbia Press.

Tesar, B. 2014. Output-driven phonology. Cambridge: Cambridge University Press.

Tesar, B. and P. Smolensky. 2000. Learnability in Optimality Theory. Cambridge, MA: The MIT Press.

Thomas, G. 2008. An analysis of the Xiamen tone circle. In N. Abner and J. Bishop (eds.) Proceedings of the $27^{\text {th }}$ West Coast Conference on Formal Linguistics. Somerville, MA: Cascadilla Proceedings Project. pp. 422-430.

Truckenbrodt, H. 1999. On the relation between syntactic phrases and phonological phrases. Linguistic Inquiry 30(2): 219-255. https://doi.org/10.1162/002438999554048

Wang, W.S.-Y. 1967. Phonological features of tone. International Journal of American Linguistics 33(2): 93-105.

Wee, L.-H. 2002. Of chains and weights. Handout for seminar series Grammaticality of the Fittest, City University of Hong Kong.

Yip, M. 1980. The Tonal Phonology of Chinese. Unpublished PhD dissertation, Massachusetts Institute of Technology. 
Yuan, J. 1989. Hanyu fangyan gaiyao ['An overview of Han dialects']. Beijing: Wenzi Gaige Chubanshe.

Yun, W. 1987. Hainan fangyan ['Hainan dialect']. Macau: University of Macau Press.

Zhang, J. 2002. The effects of duration and sonority on contour tone distribution - A typological survey and formal analysis. New York: Routledge. https://doi.org/10.4324/9781315024134

Zhang, J. and Y. Lai. 2008. Phonological knowledge beyond the lexicon in Taiwanese reduplication. In Y.E. Hsiao, H. Hsu, L.-H. Wee and D. Ho (eds.) Interfaces in Chinese phonology. Taipei: Institute of Linguistics, Academia Sinica. pp. 183-222.

Zhang, J., Y. Lai and C. Sailor. 2011. Modeling Taiwanese speakers' knowledge of tone sandhi in reduplication. Lingua 121(2): 181-206. https://doi.org/10.1016/j.lingua.2010.06.010 